\title{
BIM-ENABLED FACILITY MANAGEMENT OPTIMIZATION BASED ON POST-OCCUPANCY EVALUATIONS AND BUILDING MONITORING: FRAMEWORK AND FIRST RESULTS
}

\author{
ELENA SEGHEZZI, GIUSEPPE MARTINO DI GIUDA, MARCO SCHIEVANO, and \\ FRANCESCO PALEARI \\ Dept of Architecture, Built Environment and Construction Engineering, Politecnico di \\ Milano, Milano, Italy
}

\begin{abstract}
This paper provides a methodological definition and the first setting of a BIM-enabled Facility Management approach for building stocks, to be applied to O\&M contracts, based on Post-Occupancy Evaluation (POE) methods. The use of BIM, combined with advanced monitoring techniques, facilitates the development of effective decisionmaking approaches for the operational stage of the building Life Cycle. Information obtained through POEs performed on real-time data can converge in the BIM model and related database- of the building, to be used as a data repository and as the base for future scenarios analyses, simulating potential optimizations in facility management. This approach is being applied and tested in a case study building. This work is developed by analyzing current FM techniques, followed by the installation of sensors and cameras in the case study building, monitoring current usage patterns. Post Occupancy Evaluation analyses are then carried out to define an updated and more efficient FM scenario. Further developments in this sense regard the development of a mobile application providing permanent monitoring of the O\&M conditions and the setting of Smart Contracts for FM. This approach could facilitate optimization of space use, an increase in quality of O\&M activities, and optimization of the contractual aspects of facility management.
\end{abstract}

Keywords: Building management system, Building sensors, Operation and maintenance, Usage patterns, Building monitoring, Smart contract.

\section{INTRODUCTION}

Designers, contractors, and clients' attention is typically kept mainly on construction costs; nonetheless, operating costs of buildings represent the most relevant part of its life cycle costs. It is proven that they account for up to $70 \%$ of total Life Cycle Costs (Bortolini and Forcada 2020). Even though building management systems are scarcely used, and the availability of tools and methods specifically designed for the operating phase of building Life Cycle is limited (Patacas et al. 2015).

Besides costs, the operating phase of a building plays a relevant role in the evaluation of the quality of internal environment, users' satisfaction, safety and correspondence to legislative requirements, and energy consumptions. 
The improvement and facilitation of Facility Management (FM) for building owners is a crucial aspect to decrease operational costs on the one hand, and to increase building users' satisfaction (Choi et al. 2012, Kwon et al. 2011). In this context, the use of a BIM approach for FM represents an interesting integration that can help to overcome some limitations and current issues of operational phases: its implementation is still limited to case studies or experiments (Codinhoto and Kiviniemi 2014). Many research works are available exploring the potential of this integration, but the proper implementation and case study application is not widely diffused (Oti et al. 2016). The goal of the proposed research is the definition of a building management system based on a BIM model that integrates data from building sensors and Post-Occupancy Evaluations to optimize facility management. The setting of this system is here presented, together with the first steps of the research application on a case study building.

\section{METHODOLOGY}

This paper provides the setting of the system to be used to improve FM operations in existing building, based on Post-Occupancy evaluations, and the use of building sensors. The system proposed aims at three main optimizations: space use, operations and maintenance management, and contracts management, in accordance with the client. The chosen case study is an office building that is currently not under monitoring. No data related to effective space use is available and cleaning and maintenance operations are currently not optimized; in addition, no space optimization has been performed in relation to the use of available rooms, and the quantity of people that is effectively in the building.

The goal of this research is therefore to provide both an optimization of current O\&M management, and the application of Smart Contract to cleaning and maintenance services. The general setting of the method is summarized in Figure 1:

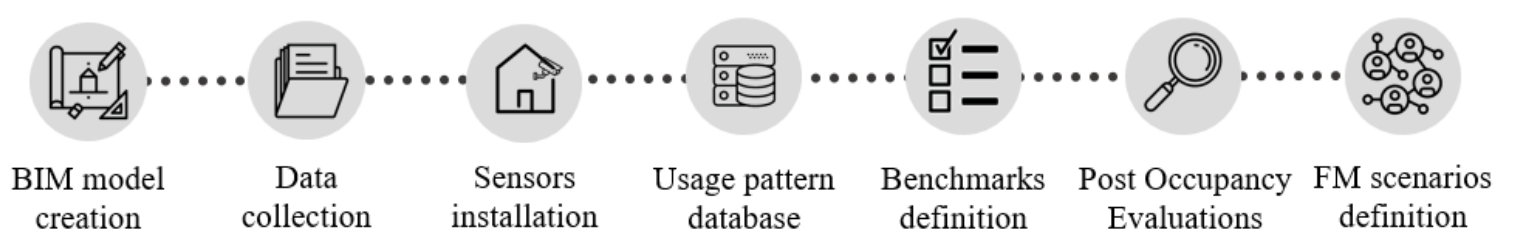

Figure 1. Setting of the methodology.

Preliminary activities include the definition of a BIM model of the building and a data collection of current O\&M activities, as well as the current use of spaces in the building. BIM for FM, despite its relatively low maturity, could result in several benefits, including the improvement of customer services, the reductions of time and cost resulting from better forecasts and planning capabilities (Oti et al. 2016). Data consistency when using a BIM approach, has also proven to clearly increase (Codinhoto and Kiviniemi 2014).

Building sensors are then installed to collect relevant information. In the presented case study, the sensors are cameras collecting information about the use of spaces (people going in and going out). Due to privacy reasons, the cameras do not store proper images but translate them into data regarding the number of users for each room (per day and per week) and the occupation of each room, measured in hours per day. The cameras are installed in the main corridors of the building and provide a view of all the office spaces, as well as bathrooms and relax areas. Once data from sensors are collected, it is possible to identify usage patterns of the building spaces. Post Occupancy Evaluations are based on the definition of reference benchmarks to evaluate 
collected data (Pärn et al. 2017). These benchmarks were discussed and set together with the client to suit its necessities and requirements.

Considering cleaning activities, the benchmark set is the number of people, the quantity of time between cleaning operations, and the cleaning standard of each room.

Data collected are then analyzed to evaluate the current management of spaces in terms of people's permanence and cleaning frequency.

\section{POST OCCUPANCY EVALUATIONS AND USAGE PATTERNS}

Post Occupancy Evaluations are a solid approach to assess the effective performance of existing buildings (Candido et al. 2016) and consequently defining interventions to increase the performance and the building user's satisfaction. In general, the main interest of POEs is related to Indoor Environmental Quality, which has proven to strongly affect the productivity of building users (Choi et al. 2012). The definition of IEQ is wide and includes factors related to building materials, thermal and lighting conditions, air quality, space assessment. Assuring a constant evaluation of these factors during the building Life Cycle is a key strategy to guarantee its quality and sustainability (Coates et al. 2012).

In this case, evaluations to be carried out regarding (i) the evaluation of the number of interventions to reach the cleaning standard required, depending on the real crowding of spaces; (ii) the evaluation of the number of cleaning personnel required to reach the standard, and (iii) the evaluation of actual requirements in terms of supply of goods, especially related to toilet facilities. Information on the occupancy of the building, the functions performed, the internal conditions of the rooms, the management of air quality and air conditioning will constitute the usage pattern of the building. A subsequent comparison of the used model with the current situation planned on a project basis will identify any differences between the building and the functional scheme of the project. The proposed POEs are based on both existing data related to building cleaning and maintenance operations, and on data coming from building sensors (Candido et al. 2016, Coates et al. 2012, Liu and Akinci 2009). The integration of data collected, and users' surveys will be investigated to provide a complete overlook in terms of customer satisfaction and quality reaching.

\section{BUILDING MONITORING AND BIM INTEGRATION}

BIM for Facility Management, as previously stated, plays a key role as a data repository; BIM models shall not be considered as a static representation of reality but as simulation (Coates et al. 2012) to reach the goal of a building operational model.

The integration of data coming from sensors with a BIM model could provide relevant benefits, e.g., the possibility of a real-time comparison of the building performance against defined benchmarks and the improvement in data communication and visualization (Peng et al. 2017). After the data collection phase and the integration of data and model, it is possible to define intervention scenarios for the simulation of changes in building management, aimed at achieving the objectives set as benchmarks. In particular, alternative plans for the management of cleaning activities will be defined. Other intervention scenarios regard changes in the use and allocation of space in accordance with the data obtained from monitoring and the identified use model. In this phase, it will also be possible to validate the current cleaning process management system by comparing the current system with the alternative cleaning processes developed. 


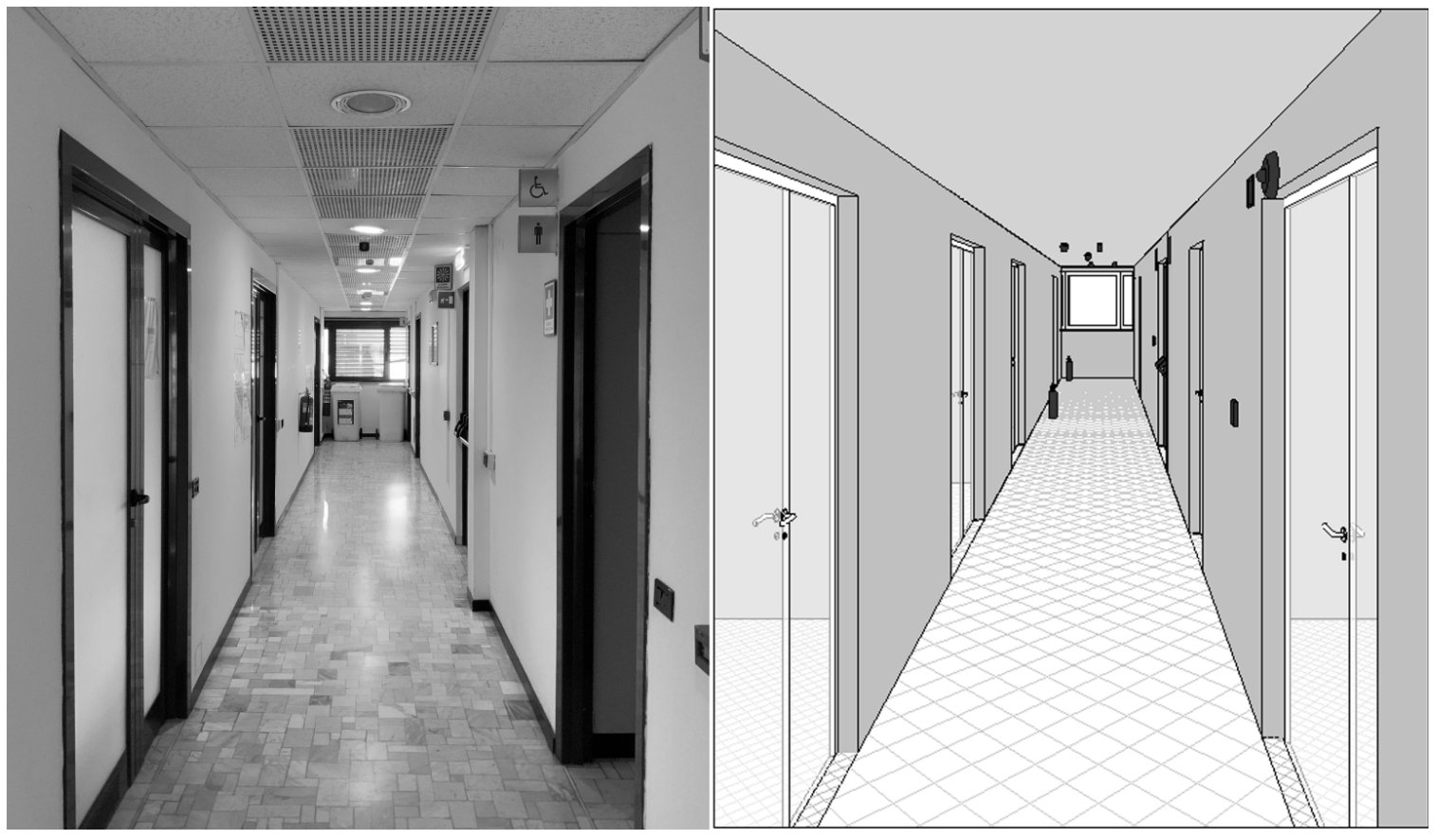

Figure 2. Camera sensors installed in the building corridor.

As previously stated, the first part of this research regards the use of cameras as sensors, as shown in Figure 2. Further developments regard the possibility of building monitoring through IAQ (Indoor Air Quality), humidity, and $\mathrm{CO}_{2}$ sensors, to provide a complete evaluation of the building indoor environmental quality.

\section{SMART CONTRACTS AND BLOCKCHAIN IMPLEMENTATION}

A relevant goal of the building management system is the combination of the proposed methodology with Smart contracts and Blockchain technology. Blockchain technology, combined with a BIM approach, provides relevant advantages, as it increases network security, reliable data storage, ensuring traceability (Nawari and Ravindran 2019). The implementation of the building's existing information environment (BIM) using Blockchain technology supports creating an information database containing data from sensors installed inside the building. The final phase of optimizing FM of the building regards the automation of payments for cleaning activities by Smart Contract (Di Giuda et al. 2020, Ye et al. 2018). The integration of BIM methodology and Blockchain technology for the building management allows executing Smart Contracts that are coded contracts, capable of executing the clauses established and shared by the contracting parties automatically and autonomously. The implementation of these contracts makes it possible to automate the execution of cleaning service contracts and, consequently, the related payments (Turk and Klinc 2017). The advantages related can be summarized as the certainty of information content detected and archived, as well as the speed and independence of contract execution. 


\section{CONCLUSIONS}

The method proposed is at its starting phases; nonetheless, some results are already available, together with some considerations. In the first place, the development of a building management system is an interesting and complex activity with promising effects on the efficiency of the building itself. It is particularly relevant to create a solid relationship with the building owner and manager, to properly understand management techniques, procedures, and protocols currently in use. This cooperation should be carried out during the entire project to provide immediate feedback.

During the setting of the sensors, it has appeared essential to properly communicate with the building users in order to guarantee stable feedback and to avoid any perception of intrusive control due to the sensors installed (Hellwig 2015), both from office workers and from cleaning personnel. In this sense, the integration of POEs with users' opinions expressed in surveys represent an encouraging step to reach better results.

Considering building monitoring, as previously stated, the potential application of different types of sensors could result in a complete evaluation of the building condition; in addition, sensors could play a role in the safety management of the building, identifying risks and mandown situations.

The proposed method, once tested and refined on the case study building, could be extended to large building stock, providing a decision-making tool for building owners and building managers.

\section{References}

Bortolini, R., and Forcada, N., Analysis of Building Maintenance Requests Using a Text Mining Approach: Building Services Evaluation, Building Research and Information, 48(2), 207-217, 2020.

Candido, C., Kim, J., De Dear, R., and Thomas, L., BOSSA: A Multidimensional Post-Occupancy Evaluation Tool, Building Research and Information, 44(2), 214-228, 2016.

Choi, J. H., Loftness, V., and Aziz, A., Post-Occupancy Evaluation of 20 Office Buildings as Basis for Future IEQ Standards and Guidelines, Energy and Buildings, 46, 167-175, 2012.

Coates, P., Arayici, Y., and Ozturk, Z., New Concepts of Post Occupancy Evaluation (POE) Utilizing BIM Benchmarking Techniques and Sensing Devices Smart Innovation, Systems and Technologies, 12(January), 319-329, 2012.

Codinhoto, R., and Kiviniemi, A., BIM for FM: A Case Support for Business Life Cycle, In 11th IFIP International Conference on Product Lifecycle Management (PLM), 1-12, 2014.

Di Giuda, G. M., Pattini, G., Seghezzi, E., Schievano, M., and Paleari, F., The Construction Contract Execution Through the Integration of Blockchain Technology, In Digital Transformation of the Design, Construction and Management Processes of the Built Environment, 27-36 Springer International Publishing, 2020.

Hellwig, R. T., Perceived Control In Indoor Environments: A Conceptual Approach, Building Research and Information, 43(3), 302-315, 2015.

Kwon, S. H., Chun, C., and Kwak, R. Y., Relationship Between Quality of Building Maintenance Management Services for Indoor Environmental Quality and Occupant Satisfaction, Building and Environment, 46(11), 2179-2185, 2011.

Liu, X., and Akinci, B., Requirements and Evaluation of Standards for Integration of Sensor Data with Building Information Models, Proceedings of the 2009 ASCE International Workshop on Computing in Civil Engineering, 346, 95-104, 2009.

Nawari, N. O., and Ravindran, S., Blockchain Technology and BIM Process: Review and Potential Applications, Journal of Information Technology in Construction, 24(May), 209-238, 2019.

Oti, A. H., Kurul, E., Cheung, F., and Tah, J. H. M., A Framework for The Utilization of Building Management System Data in Building Information Models for Building Design and Operation, Automation in Construction, 72, 195-210, 2016.

Pärn, E. A., Edwards, D. J., and Sing, M. C. P., The Building Information Modelling Trajectory in 
Facilities Management: A Review, Automation in Construction, 75, 45-55, 2017.

Patacas, J., Dawood, N., Vukovic, V., and Kassem, M., BIM for Facilities Management: Evaluating BIM Standards in Asset Register Creation and Service Life Planning, Journal of Information Technology in Construction, 20(August 2016), 313-331, 2015.

Peng, Y., Lin, J. R., Zhang, J. P., and Hu, Z. Z., A Hybrid Data Mining Approach on BIM-Based Building Operation and Maintenance, Building and Environment, 126(September), 483-495, 2017.

Turk, Ž., and Klinc, R., Potentials of Blockchain Technology for Construction Management, Procedia Engineering, 196(June), 638-645, 2017.

Ye, Z., Yin, M., Tang, L., and Jiang, H., Cup-of-Water theory: A Review on The Interaction of BIM, IoT and Blockchain During the Whole Building Lifecycle, ISARC 2018 - 35th International Symposium on Automation and Robotics in Construction and International AEC/FM Hackathon: The Future of Building Things, (Isarc), 2018. 